\title{
Flora das cangas da Serra dos Carajás, Pará, Brasil: Menyanthaceae
}

\author{
Flora of the cangas of the Serra dos Carajás, Para, Brazil: Menyanthaceae
}

Ana Maria Giulietti ${ }^{1,2}$

\begin{abstract}
Resumo
Este estudo traz a família Menyanthaceae nas cangas da Serra dos Carajás, no estado do Pará. Contém descrições detalhadas, ilustrações e comentários morfológicos de Nymphoides humboldtiana, a única espécie da área, a qual possui distribuição Neotropical.

Palavras-chave: Amazônia, flora, Floresta Nacional de Carajás, taxonomia.
\end{abstract}

\begin{abstract}
This study includes the species of Menyanthaceae registered for the cangas of the Serra dos Carajás, Pará state, providing detailed descriptions, illustrations, and morphological comments of Nymphoides humboldtiana the only species registered, which is widely distributed in the Neotropics.
\end{abstract}

Key words: Amazonia, flora, National Forest of Carajás, taxonomy.

\section{Menyanthaceae}

Menyanthaceae compreende cinco gêneros e cerca de 35 espécies, sendo Nymphoides o que inclui o maior número de espécies (Kadereit 2007; Tippery et al. 2008). A família inclui ervas aquáticas ou semiaquáticas, anuais a perenes, rizomatosas, com folhas alternas, simples, geralmente com formas que variam de reniformes ou cordiformes a orbiculares e peltadas. As flores são isoladas ou reunidas em inflorescências racemosas ou fasciculadas, bissexuadas e geralmente distílicas, pentâmeras e actinomorfas, com corola gamopétala com lobos com margem fimbriada ou cristada, o androceu é isostêmone e o gineceu é bicarpelar, com ovário súpero unilocular e placentação parietal. $\mathrm{O}$ fruto é do tipo cápsula, com sementes numerosas.

Na Serra dos Carajás, foi registrada apenas Nymphoides humboldtiana (Kunth) Kuntze que ocorre como espécie perene nas lagoas da área de estudo.

\section{Nymphoides Ség.}

O gênero Nymphoides inclui cerca de 20 espécies, possui distribuição pantropical, ocorrendo nas Américas, África, Austrália e Ásia, tendo nesses dois últimos continentes a maior diversidade (Yatskievych 2001; Kadereit 2007; Tippery \& Les 2011). De acordo com Barcelos $\&$ Bove (2016) ocorrem no Brasil, Nymphoides grayana (Griseb.) Kuntze e N. humboldtiana. As espécies do gênero são ervas aquáticas, com folhas flutuantes, orbiculares ou largamente ovais, peltadas e de base cordada e as flores distílicas são reunidas em fascículos axilares.

\subsection{Nymphoides humboldtiana (Kunth) Kuntze, Revis. Gen. pl. 2: 429. 1891.}

Fig. 1a-h

Ervas aquáticas, rizomatosas, perenes. Folhas com pecíolos 13-24 cm compr., limbos flutuantes, largo-ovais a orbiculares, 5-15 $\times 5-15 \mathrm{~cm}$, membranáceos a ligeiramente cartáceos, ápice arredondado a ligeiramente emarginado, base cordada, lobos basais $2-5 \mathrm{~cm}$ comp., discolores ou não. Flores em fascículos axilares, 5-10 emergindo próximo à base do limbo, ca. 1,5 cm diâm.; pedicelos $2-5 \mathrm{~cm}$ compr.; sépalas 5-7 mm compr., verdes com ápices avermelhados; corola com tubo curto, lobos 5, lanceolados, acuminados, 1,1-1,3 cm compr., face adaxial branca com base amarelada, densamente pilosa, margem fimbriada; estames

\footnotetext{
'Instituto Tecnológico Vale de Desenvolvimento Sustentável, R. Boaventura da Silva 955, Nazaré, 66055-090, Belém, PA, Brasil.

${ }^{2}$ Autor para correspondência: ana.giulietti@itv.org
} 


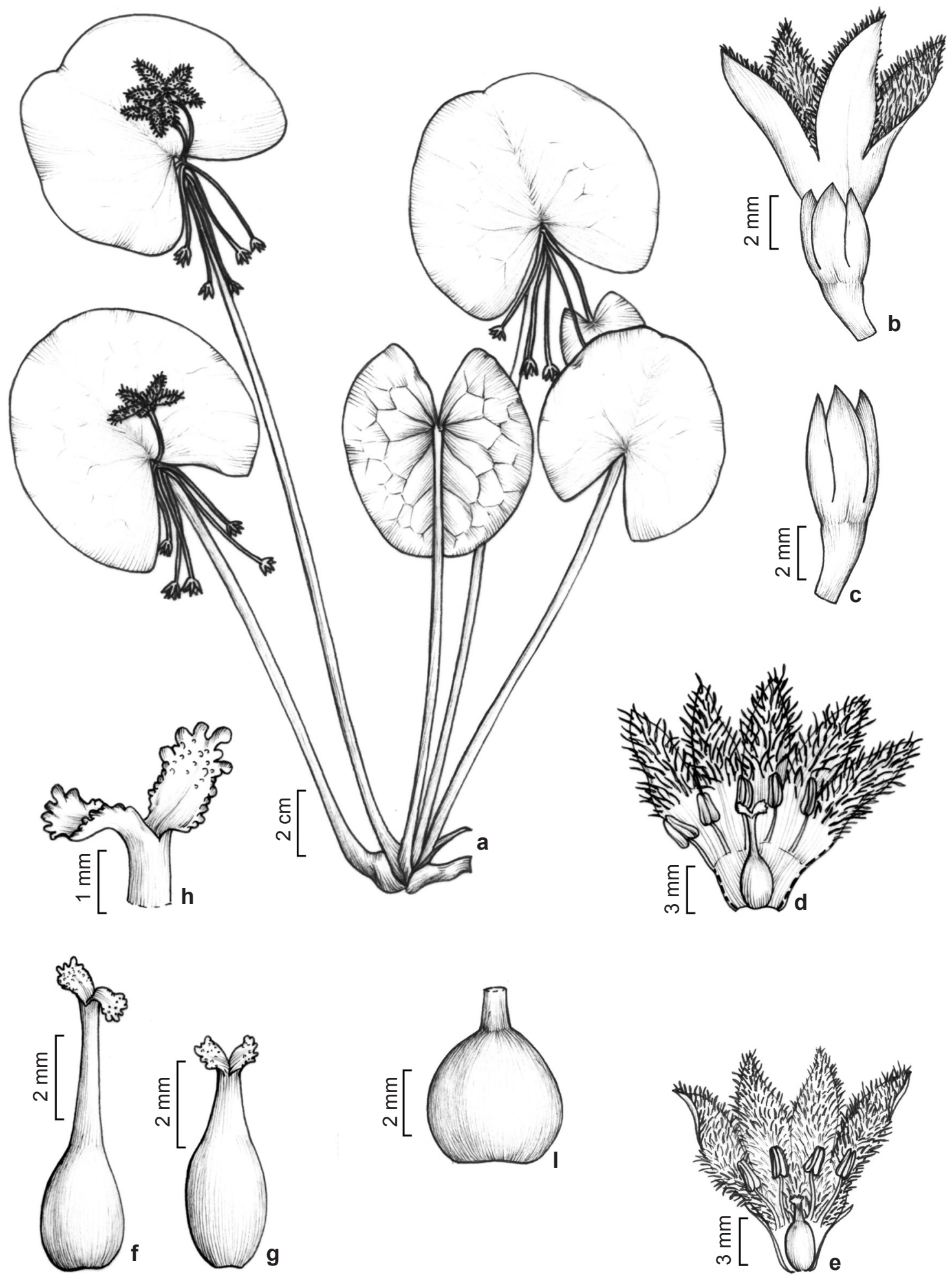

Figura 1 - Nymphoides humboldtiana - a. hábito; b. flor mostrando cálice e corola; c. cálice, d. flor em antese; e. flor jovem; f-g. gineceu mostrando variação no tamanho do estilete; $h$. detalhe do estigma bilobado; i. fruto jovem. Figure 1 - Nymphoides humboldtiana - a. habit; b. flower, showing calyx and corolla; c. calyx; d. flower in anthesis; e. opened young flower; f-g. gynoecium showing the variation in style size; h. detail of the bilobed stigma; i. young fruit. 
5, filetes $3-5 \mathrm{~mm}$ compr., anteras enegrecidas; gineceu $0,6-0,8 \mathrm{~cm}$ compr., atingindo metade da altura dos filetes, estilete linear, estigma bilobado, ovário multiovulado. Cápsula ovóide.

Material selecionado: Canaã dos Carajás, S11A, $6^{\circ} 20^{\prime} 58^{\prime \prime}$ 'S, 50 '26'57' 'W, rampa de acesso a Lagoa Três Irmãs, 17.IV.2015, fl. e fr., L.M.M. Carreira et al. 3405 (MG); Estrada S11D-S11A, 22.III.2015, fl., L.C. Lobato 4379 (MG). Parauapebas, N1, 31.V.1986, fr., M.P.M. Lima et al. 56 (MG); N4, 15.III.1984, fl., A.S.L. Silva 1809 (MG); N8, 18.III.2015, fl., L.C. Lobato 4346 (MG).

Nymphoides humboldtiana tem distribuição Neotropical, ocorrendo desde o sul dos Estados Unidos até o Uruguai (Ordnuff 1969; Tippery \& Les 2011). A espécie tem sido referida para o Brasil com o nome de $N$. indica (L.) (BFG 2015). Nesse trabalho seguimos a proposta feita por Giulietti et al. (2015), onde foi apresentada longa discussão sobre o nome a ser aceito para a espécie. Barcelos \& Bove (2016) também aceitam a denominação de Nymphoides humboldtiana para a espécie mais amplamente distribuída no país, a qual ocorre do Amazonas até o Rio Grande do Sul.

Nas Serras de Carajás, a espécie ocorre em praticamente todas as lagoas e forma grandes populações associada a outras espécies aquáticas. Durante o período de seca (julho a dezembro), com a redução do nível de águas, muitas lagoas secam totalmente, possibilitando a observação de restos das folhas e dos caules presos na lama sobre as cangas. Floresce praticamente durante todo o ano, mas com maior intensidade no período das chuvas entre fevereiro e junho. Todos os indivíduos examinados apresentaram flores pentâmeras, diferentemente do que ocorre com os indivíduos que ocorrem na Bahia que podem apresentar flores pentâmeras ou tetrâmeras (Giulietti et al. 2015).

\section{Agradecimentos}

Agradecemos ao Museu Paraense Emílio Goeldi e ao Instituto Tecnológico Vale, a estrutura e o apoio fundamentais ao desenvolvimento desse trabalho. Aos curadores dos herbários consultados, o acesso aos materiais examinados. Ao ICMBio, especialmente ao Frederico Drumond Martins, a licença de coleta concedida e o suporte nos trabalhos de campo. A Carla Lima, a confecção das ilustrações. Ao CNPq, a bolsa Senior. Ao Instituto Tecnológico Vale (01205.000250/201410) e ao CNPq (processo 455505/2014-4), o financiamento do projeto.

\section{Referências}

Barcelos, F.R.B. \& Bove, C.P. 2016. Menyanthaceae. In: Flora do Brasil 2020 [em construção]. Jardim Botânico do Rio de Janeiro. Disponível em <http:// floradobrasil.jbrj.gov.br/reflora/floradobrasil/ FB164>. Acesso em 3 agosto 2016

BFG. 2015. Growing knowledge: an overview of seed plant diversity in Brazil. Rodriguésia 66: 10851113.

Giulietti, A.M.; Santa Izabel, T.S. \& Oliveira, R. P. 2015. Flora da Bahia: Menyanthaceae. Sitientibus, Série Ciências Biológicas 754:1-5.

Kadereit, J.W. 2007. Menyanthaceae. In: Kubitzki, K; Kadereit, J.W. \& Jeffrey, C. (eds.). The families and genera of vascular plants. Vol. 8. SpringerVerlag, Berlin. Pp. 589-604.

Ornduff, R. 1969. Neotropical Nymphoides (Menyanthaceae): Meso-American and West Indian species. Brittonia 21: 346-351.

Tippery, N.P.; Les, D.H.; Padgett, D.J. \& Jacobs, W.L. 2008. Generic circumscription in Menyanthaceae: a phylogenetic evaluation. Systematic Botany 33: 598-612.

Tippery, N.P. \& Les, D.H. 2011. Phylogenetic relationships and morphological evolution in Nymphoides (Menyanthaceae). Systematic Botany 36: 11-1113.

Yatskievych, K. 2001. Menyanthaceae. In: Steyermark, J.A.; Berry, P.E. \& Holst, B.H. (eds.), Flora of the Venezuelan Guayana. Vol. 6. Missouri Botanic Garden Press, Saint Louis. Pp. 578-579.

\section{Lista de exsicatas}

Carrera, L.M.M. 1055, 1071, 3405, 3460; Lima, M.P.M. 56; Lobato, L.C. 3855, 4346, 4379; Secco, R. 194, 297; Silva, A.S.L. 1809, 1854; Silva, M.G. 3030 . 
